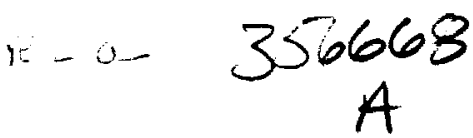

1998397295

$1 N-39$

\title{
Progressive Damage and Fracture of Unstiffened and Stiffened Composite Pressure Vessels
}

\author{
LEVON MINNETYAN* \\ Department of Civil and Environmental Engineering \\ Clarkson University \\ Potsdam, NY 13699-5710 \\ Pascal K. Gotsis AND Christos C. Chamis \\ National Aeronautics and Space Administration \\ Lewis Research Center \\ Cleveland, OH 44135 \\ (Received December 1996) \\ (Revised January 1997)
}

\begin{abstract}
Structural durability and damage tolerance characteristics of pressurized graphite/epoxy laminated thin composite cylinders are investigated via computational simulation. Both unstiffened and integral hoop stiffened cylinders are considered. A computer code is utilized for the simulation of composite structural degradation under loading. Damage initiation, growth, accumulation, and propagation to structural fracture are included in the simulation. The increase of burst pressure due to hoop stiffening is quantified. Results demonstrate the significance of the type and size of local defects on the structural durability of pressurized composite cylindrical shells.
\end{abstract}

KEY WORDS: burst pressūre, composites, composite structures, damage, degradation, durability, fracture, laminates, pressure vessels, simulation, structural fracture.

\section{INTRODUCTION}

AMINATED COMPOSITE CYLINDRICAL shell structures are used in many diverse Japplications such as advanced aircraft fuselage, rocket motor cases, pressure

No copyright is asserted in the United States under Title 17, U.S. Code. The U.S. govemment has a royalty-free licence to exercise all rights under the copyright claimed herein for government purposes. All other rights are reserved by the copyright owner.

-Author to whom correspondence should be addressed; Tel.: (315)268-7741; FAX: (315)268-7985; E-mail levon@sun.soe.clarkson edu.

Reprinted from Journal of REINFORCIO) Pi.ASTICS AND CoMPOSITES, Vil. 16, No. $18 / 1997$ 
vessels, containment structures, pipelines, and other pressurized components with various shapes and sizes. In these applications composite shells are required to withstand significant internal pressures. Design considerations with regard to the durability of composite shell structures require an evaluation of damage initiation and propagation mechanisms under expected service pressures. Concerns for safety and survivability of critical components require a quantification of the composite structural fracture resistance and damage tolerance.

Stiffened composite shells are used to achieve light weight as well as high strength and stiffness. For certain designs, structural interactions between skin and stiffener may adversely affect durability, especially in the presence of defects. The computational simulation method used in this paper is well suited to investigate and identify the effects of stiffener interactions on damage and fracture propagation under design loads and overloads.

The availability of many options in the fabrication of a laminate structure make composites more capable of fulfilling structural design requirements. However, the presence of those same design choices render the assessment of composite structural response and durability more elaborate, prolonging the design process. It is difficult to design and certify composite structures because of the complexities in predicting the overall congruity and performance of laminated composites under various loading and environmental conditions.

Any inadvertent ply damage such as transverse cracks, accidental ply cuts during fabrication and service, and defect induced fiber fractures could weaken the overall structural strength and durability. It is neither practical nor feasible to design a composite structure to resist inadvertent damage at all times. A more practical approach is to allow for the existence of local defects due to accidental damage, material defect, or fabrication error. Defects may or may not affect durability for a particular structure. It is therefore useful to quantify the reduction in the overall strength and durability of a composite shell structure due to preexisting defects and accidental damage.

Composite shells may be classified into a number of categories depending on their geometry and functional characteristics. Discussion in the current paper is focussed on thin cylindrical shells subject to internal pressure. Five cases of composite shells are considered as follows: (1) unstiffened defect-free shell, (2) unstiffened shell with small axial slit, (3) unstiffened shell with superimposed axial and hoop compound slits, (4) defect-free shell with hoop stiffeners, (5) defective shell with hoop stiffeners. Damage initiation, growth, accumulation, and propagation to fracture is simulated for each case. The influences of existing slits and partial-thickness ply fiber cuts due to fabrication errors or inadvertent damage are examined with regard to damage progression and structural durability under applied loading. Changes in the damage initiation load and the structural fracture load are quantified due to the presence of partial-thickness defects, through-the-thickness axial slits, and through-the-thickness compound slits in shells.

The following terminology is used in this paper to describe the various stages of degradation in the composite structure: (1) initial defect refers to the inadvertent damage as well as to the material fabrication defect present in the composite structure before the application of service loading; (2) damage initiation refers to the 
start of damage induced by loading that the composite structure is designed to carry; (3) damage growth is the progression of damage from the location of damage initiation to adjacent regions; (4) damage accumulation is the increase in the amount of damage in the damaged region with additional damage modes becoming active; (5) damage propagation is the rapid progression of damage to other regions of the structure; (6) structural fracture is the ultimate disintegration or burst of the shell structure. At any stage of damage progression, if there is a high level of structural resistance to damage propagation under the service loading, the structure is stable with regard to fracture. The corresponding state of structural damage is referred to as stable damage. On the other hand, if damage progression does not encounter significant structural resistance, it corresponds to an unstable damage state. Unstable damage progression is characterized by very large increases in the amount of damage due to very small increases in loading.

\section{METHODOLOGY}

The progressive damage and simulation methodology was developed in the CODSTRAN (COmposite Durability STRuctural ANalysis) computer code [1] that has been implemented to predict the behavior of composite structures for any loading, geometry, composite material combinations, and boundary conditions. CODSTRAN is an integrated, open-ended, stand alone computer code consisting of three modules: composite mechanics, finite element analysis, and damage progression modeling. The overall evaluation of composite structural durability is carried out in the damage progression module [1] that keeps track of composite degradation for the entire structure. The damage progression module relies on ICAN [2] for composite micromechanics, macromechanics and laminate analysis, and calls a finite element analysis module that uses anisotropic elements to model laminated composites [3]. The CODSTRAN code has been used to investigate the effects of composite degradation on structural response [4], effect of hygrothermal environment on durability [5], damage progression in thin composite pressure vessels with partial-thickness defects [6], an overall evaluation of progressive fracture in polymer matrix composite structures [7], and the durability of discontinuously stiffened composite panels under compressive loading [8]. The purpose of this paper is to describe simulated damage progression in stiffened and unstiffened composite shell structures with and without through-the-thickness slits to evaluate burst pressures taking into account damage initiation/propagation mechanisms.

The ICAN composite mechanics module is called before and after each finite element analysis. Prior to each finite element analysis, the ICAN module computes the composite properties from the fiber and matrix constituent characteristics and the composite layup. The finite element analysis module uses four-node anisotropic thick shell elements to model laminated composites [3]. The generalized stress-strain parameters for each element consist of the in-plane normal and shear $N_{x}, N_{y}, N_{x y}$, out-of-plane shear $S_{x z}, S_{y z}$, and bending $M_{x}, M_{y}, M_{x y}$ stress resultants and the corresponding $\varepsilon_{x}, \varepsilon_{y}, \varepsilon_{x y}, \gamma_{x z}, \gamma_{y z}, \kappa_{x}, \kappa_{y}, \kappa_{x y}$, strains/curvatures. The finite element analysis module accepts the composite properties that are computed by the ICAN module at each node and performs the analysis at each load increment. After an in- 
cremental finite element analysis, the computed generalized nodal force resultants and deformations are supplied to the ICAN module that evaluates the nature and amount of local damage, if any, in the plies of the composite laminate. Individual ply failure modes are determined by ICAN using failure criteria associated with the negative and positive limits of the six ply-stress components, interply delamination due to relative rotation of the plies, and a modified distortion energy (MDE) failure criterion that takes into account combined stresses [2]. The MDE failure criterion is obtained by modifying the usual distortion energy failure criterion that predicts combined stress failure in isotropic materials. The modification takes into account the significant differences in the stress limits of the longitudinal and transverse directions of an orthotropic composite ply. Each component of ply stress is normalized with respect to its limiting strength. No relationship is assumed between normal and shear strengths.

The MDE criterion has been demonstrated to be a good predictor of combined stress failure in composites. Details of the MDE criterion, as well as other options for the assessment of local failure in composites are given in Reference [2]. If the MDE criterion predicts a failure, the type of failure is assessed by first identifying the dominant stress component. The dominant stress component is defined to have the largest ratio of actual stress to the corresponding strength. If the dominant stress term in the MDE failure criterion is a longitudinal stress component then ply fiber and matrix failures are assigned. On the other hand, if the dominant stress is a transverse or shear stress component then only matrix failure is assigned. The generalized stress-strain relationships for each node are revised according to the composite damage evaluated after each finite element analysis. The model is automatically updated with a new finite element mesh having reconstituted properties, and the structure is reanalyzed for further deformation and damage. The reconstituted finite element properties are supplied by the composite mechanics module, taking into account the reduced fiber and matrix stiffnesses at the degraded plies. The finite element mesh is also updated when nodes are failed because of through-thethickness laminate fracture. If there is no damage after a load increment, the structure is considered to be in equilibrium and an additional load increment is applied. Simulation is stopped when global structural fracture is predicted.

The incremental loading procedure for progressive damage and fracture tracking uses an accuracy criterion based on the allowable maximum number of damaged and fractured nodes within a simulation cycle during the application of a load increment. If too many nodes are damaged or fractured in a simulation cycle, incremental loads are reduced and the analysis is restarted from the previous equilibrium state. Otherwise, if there is an acceptable amount of incremental damage, the load increment is kept constant but the constitutive properties and the structural geometry are updated to account for the damage and deformations from the last simulation cycle. The maximum number of nodes that are allowed to sustain ply damage and the number of nodes that are allowed to sustain through-the-thickness laminate fracture during any iteration cycle are selected by the user as input parameters. For the simulations presented in this paper a maximum of four nodes were allowed to degrade with ply damage or to experience through-the-thickness laminate fracture at any iteration. 
When all modes of composite resistance fail at a node, that node is deleted and new detached nodes are created at the same point for the remaining adjacent finite elements. The number of new nodes created in place of a deleted node is equal to the number of elements that had connectivity to that deleted node. In composite structures modeled via quadrilateral shell elements, if a deleted node were being shared by four elements, then four new nodes are required in place of the deleted node. When two adjacent nodes of a quadrilateral shell element are failed, that element is removed from the mesh. To remove an element, the element connectivity statement is eliminated and nodes of the removed element that do not have connectivity to any other element are deleted.

After a valid simulation cycle in which composite structural degradation is simulated with or without the possible deletion of nodes and elements, the structure is reanalyzed for further damage and deformation. If, after an incremental loading simulation cycle, there is no damage as determined by the ICAN composite mechanics module, the structure is considered to be in equilibrium and an additional load increment is applied. Analysis is stopped when global structural fracture is predicted.

\section{COMPOSITE CYLINDRICAL SHELLS}

A composite system made of AS-4 graphite fibers in a high modulus high strength epoxy matrix (AS-4/HMHS) is used. The fiber and matrix constituent properties are given in Tables 1 and 2, respectively. The thin shell laminate structure consists of eight $0.136 \mathrm{~mm}(0.00535 \mathrm{in})$ plies resulting in a composite shell thickness of $1.088 \mathrm{~mm}$ $(0.0428 \mathrm{in})$. The laminate configuration is $[90 / 0 / \pm 45]$. . The $90^{\circ} \mathrm{plies}$ are in the hoop/circumferential direction of the shell. The cylindrical shell has a diameter of 305 $\mathrm{mm}$ (12.0 in) and a length of $760 \mathrm{~mm}$ (29.9 in). The finite element model contains 544 nodes and 512 elements as shown in Figure 1. The closed-end cylindrical pressure

Table 1. AS-4 graphite fiber properties.

\begin{tabular}{lc}
\hline Number of fibers per end & 10,000 \\
Fiber diameter & $0.00762 \mathrm{~mm}(0.300 \mathrm{E}-3 \mathrm{in})$ \\
Fiber density & $1.74 \mathrm{E}+3 \mathrm{~kg} / \mathrm{m}^{3}\left(0.063 \mathrm{lb} / \mathrm{in}^{3}\right)$ \\
Longitudinal normat modulus & $227 \mathrm{GPa}(32.90 \mathrm{E}+6 \mathrm{psi})$ \\
Transverse normal modulus & $13.7 \mathrm{GPa}(1.99 \mathrm{E}+6 \mathrm{psi})$ \\
Poisson's ratio $\left(\nu_{12}\right)$ & 0.20 \\
Poisson's ratio $\left(\nu_{23}\right)$ & 0.25 \\
Shear modulus $\left(G_{12}\right)$ & $13.8 \mathrm{GPa}(2.00 \mathrm{E}+6 \mathrm{psi})$ \\
Shear modulus $\left(G_{23}\right)$ & $6.90 \mathrm{GPa}(1.00+6 \mathrm{psi})$ \\
Longitudinal thermal expansion coefficient & $1.0 \mathrm{E}-6 /{ }^{\circ} \mathrm{C}\left(-0.55 \mathrm{E}-6 /{ }^{\circ} \mathrm{F}\right)$ \\
Transverse thermal expansion coefficient & $1.0 \mathrm{E}-6 /{ }^{\circ} \mathrm{C}\left(-0.56 \mathrm{E}-6 /{ }^{\circ} \mathrm{F}\right)$ \\
Longitudinal heat conductivity & $43.4 \mathrm{~J}-\mathrm{m} / \mathrm{hr} / \mathrm{m}^{2} /{ }^{\circ} \mathrm{C}\left(580 \mathrm{Btu}-\mathrm{in} / \mathrm{hr} / \mathrm{in}^{2} /{ }^{\circ} \mathrm{F}\right)$ \\
Transverse heat conductivity & $4.34 \mathrm{~J}-\mathrm{m} / \mathrm{hr} / \mathrm{m}^{2} /{ }^{\circ} \mathrm{C}\left(58 \mathrm{Btu}-\mathrm{in} / \mathrm{hr} / \mathrm{in}^{2} /{ }^{\circ} \mathrm{F}\right)$ \\
Heat capacity & $712 \mathrm{~J} / \mathrm{kgg} /{ }^{\circ} \mathrm{C}\left(0.17 \mathrm{Btu} / \mathrm{lb} /{ }^{\circ} \mathrm{F}\right)$ \\
Tensile strength & $3,723 \mathrm{MPa}(540 \mathrm{ksi})$ \\
Compressive strength & $3,351 \mathrm{MPa}(486 \mathrm{ksi})$ \\
\hline
\end{tabular}


Table 2. HMHS epoxy matrix properties.

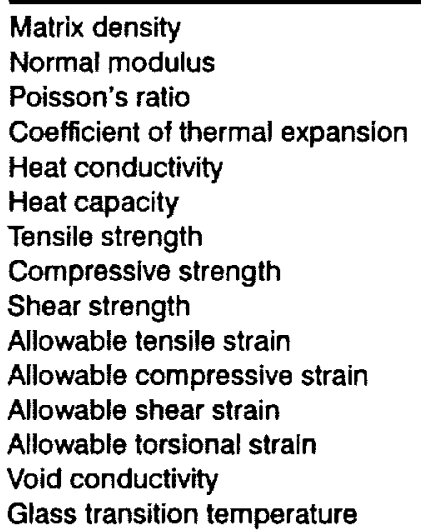

\author{
$1.26 \mathrm{E}+3 \mathrm{~kg} / \mathrm{m}^{3}\left(0.0457 \mathrm{lb} / \mathrm{in}^{3}\right)$ \\ $4.27 \mathrm{GPa}(620 \mathrm{ksi})$ \\ 0.34$$
0.72 /{ }^{\circ} \mathrm{C}\left(0.4 \mathrm{E}-4 /{ }^{\circ} \mathrm{F}\right)
$$ \\ $0.0935 \mathrm{~J}-\mathrm{m} / \mathrm{hr} / \mathrm{m}^{2} /{ }^{\circ} \mathrm{C}\left(1.25 \mathrm{Btu}-\mathrm{in} / \mathrm{hr} / \mathrm{in}^{2}{ }^{\circ} \mathrm{F}\right)$ \\ $1.05 \mathrm{E}+3 \mathrm{~J} / \mathrm{kg} /{ }^{\circ} \mathrm{C}\left(0.25 \mathrm{Btu} / \mathrm{b} /{ }^{\circ} \mathrm{F}\right)$ \\ 84.8 $\mathrm{MPa}(12.3 \mathrm{ksi})$ \\ $423 \mathrm{MPa}(61.3 \mathrm{ksi})$ \\ $148 \mathrm{MPa}(21.4 \mathrm{ksi})$ \\ 0.02 \\ 0.05 \\ 0.04 \\ 0.04 \\ $16.8 \mathrm{~J}-\mathrm{m} / \mathrm{hr} / \mathrm{m}^{2} /{ }^{\circ} \mathrm{C}\left(0.225 \mathrm{Btu}-\mathrm{in} / \mathrm{hr} / \mathrm{in}^{2}{ }^{\circ} \mathrm{F}\right)$ \\ $216^{\circ} \mathrm{C}\left(420^{\circ} \mathrm{F}\right)$
}

vessel is simulated by applying a uniformly distributed axial tension such that the generalized axial stresses in the shell wall are half those developed in the hoop direction. The composite shell is subjected to an internal pressure that is gradually increased until the shell is burst. Computational simulation takes into account the material degradation effects as well as the changes in structural geometry due to pressurization and shows the reduction in the ultimate burst pressure because of local defects in selected plies of the composite shell structure. Computed results are presented up to global fracture for defect-free and defective shells.

1. Unstiffened, defect-free shell-Computational simulation gives a damage initiation pressure of $1.05 \mathrm{MPa}$ (152 psi). Initial damage is in the form of transverse tensile fractures in the zero degree axial plies, predicted by the MDE failure criterion. When the pressure is increased to $1.31 \mathrm{MPa}$ (190 psi), transverse tensile

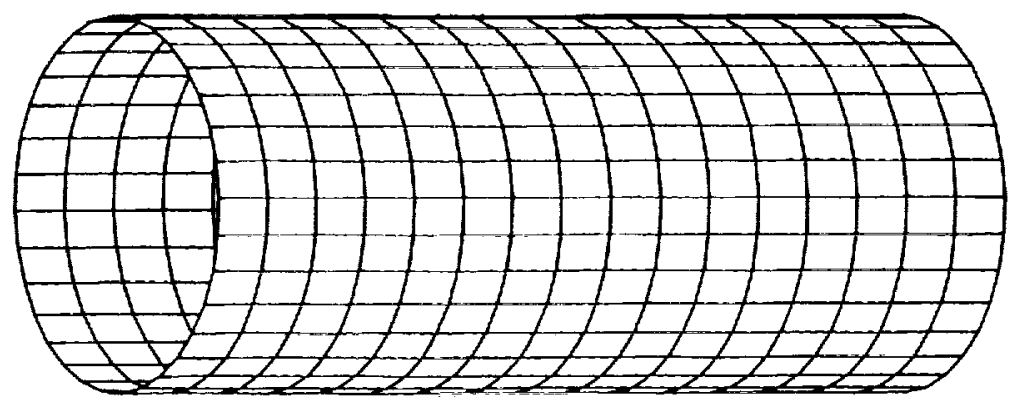

Figure 1. Finite element model of cylindrical shell. AS-4/HMHS $[90 / 0 / \pm 45]_{\mathrm{s}}$, diameter $=305$ $\mathrm{mm}$, length $=760 \mathrm{~mm}$. 
fractures spread to the \pm 45 plies. At $2.03 \mathrm{MPa}$ (295 psi) transverse tensile fractures occur in all plies. After the completion of the transverse tensile fracture phase, the pressure may be increased up to $3.00 \mathrm{MPa}(436 \mathrm{psi})$ without any additional damage. Ultimate structural fracture occurs at $3.03 \mathrm{MPa}(440 \mathrm{psi})$ due to ply longitudinal fractures in the $90^{\circ}$ hoop plies at half length of the cylindrical shell, suddenly precipitating a structural fracture.

2. Unstiffened shell with through-the-thickness slit-A composite shell with the same geometry as the defect-free specimen is modeled to have an existing 12.7 $\mathrm{mm}(0.5 \mathrm{in})$ long thin axial slit at mid-length of the shell. Damage initiation by transverse tensile fractures in the $0^{\circ}$ plies starts at $1.03 \mathrm{MPa}$ (150 psi), which is slightly lower than the pressure to cause damage initiation in the defect-free shell. The damage growth mode is significantly different from that of the defect-free shell due to localization of damage propagation at the slit. At 1.05 $\mathrm{MPa}$ (153 psi) the seven outer plies fail at the tip of the slit. However, throughthe-thickness extension of the slit does not immediately occur. Instead, damage near the slit becomes stabilized and damage progression continues by transverse tensile fractures in all $0^{\circ}$ axial plies at other locations that are not immediately adjacent to the slit. The damage stabilization phenomenon for thin cylindrical shells subjected to internal pressure has been shown previously [6].

Transverse tensile fractures of the $0^{\circ}$ axial plies due to hoop tension is completed at $1.10 \mathrm{MPa}$ (159 psi), similar to the defect-free shell. Further damage growth is concentrated near the slit. At $1.24 \mathrm{MPa}$ ( $80 \mathrm{psi})$, the first seven plies surrounding the slit fail. However, damage growth encounters well defined stages of structural resistance. Through-the-thickness structural fracture occurs at $2.01 \mathrm{MPa}(292 \mathrm{psi})$. The computed fracture load of $2.01 \mathrm{MPa}$ is 17 percent lower than an experimental measurement of the burst pressure for a similar shell [9]. It may be noted that the difference of computational simulation results from test data is well within the variability limits of in-situ fiber tensile strength.

3. Unstiffened shell with superimposed through-the-thickness compound slits - For this case the shell was modeled to have an existing severe defect in the form of a $95 \mathrm{~mm}$ ( $3.75 \mathrm{in}$ ) long thin axial slit that was superimposed on a $60 \mathrm{~mm}$ ( 2.36 in) long circumferential slit at half-length of the shell. Computational simulation results for this severely defective shell are summarized as follows.

According to simulation, damage initiation started by matrix cracking adjacent to the defect as soon as an initial pressure of $0.172 \mathrm{MPa}(25 \mathrm{psi})$ was applied. However, damage growth remained localized at the defect until a $0.745 \mathrm{MPa}$ (108 psi) pressure was reached. In the subsequent damage growth stage all plies gradually sustained transverse tensile fractures as the pressure was increased to $0.837 \mathrm{MPa}(121 \mathrm{psi})$. The damage accumulation stage that was dominated by ply transverse tensile fractures was similar to that of the defect-free shell. However, after the ply transverse tensile fracture stage was completed, the damage propagation to ultimate fracture was much more rapid compared to the defect-free shell. Damage propagation by ply longitudinal fiber fractures was concentrated near the defect. Through-the-thickness structural fracture progression occurred at $1.58 \mathrm{PMa}(230 \mathrm{psi})$, causing the cylindrical shell to burst. Figure 2 shows the finite element model as the simulated defective shell was burst. 


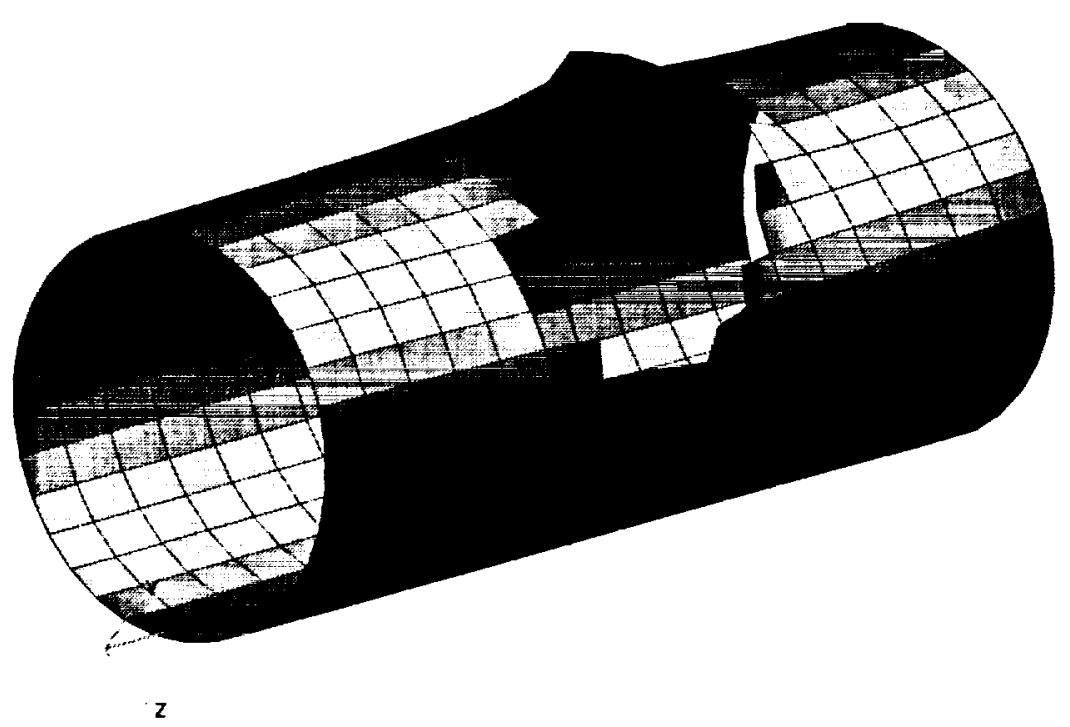

Flgure 2. Finite element model at burst of shell with compound defect. AS-4/HMHS $[90 / 0 / \pm 45]_{\mathrm{s}}$, diameter $=305 \mathrm{~mm}$, length $=760 \mathrm{~mm}$.

In general, overall structural damage may include individual ply damage and also through-the-thickness fracture of the composite laminate. Computational simulation is able to track varied and complex composite damage mechanisms via evaluation of the individual ply failure modes and associated degradation of laminate properties. The type of damage growth and the sequence of damage progression depend on the composite structure, loading, material properties, and hygrothermal conditions. A scalar damage variable, derived from the total volume of the composite material affected by the various damage mechanisms is also evaluated as an indicator of the level of overall damage induced by loading. The rate of increase in the overall damage volume during composite degradation may be used as a measure of structural propensity for fracture. The procedure by which the overall damage variable is computed is given in Reference [1].

Figure 3 shows a comparison of the overall damage progression histories for the unstiffened defect free shell, unstiffened shell with an axial slit, and unstiffened shell with a severe compound defect. The damage initiation pressure was considerably lower for the shell with the severe compound defect as compared to the other two cases. On the other hand, the damage initiation pressure was the same for the defect-free shell and the shell with $12.7 \mathrm{~mm}$ axial slit. However, the shell with the slit experienced more irregular damage growth stages as cycles of damage propagation and damage stabilization were repeated.

Damage progression characteristics may be better distinguished by quantifying a measure of structural resistance against damage propagation. The global 


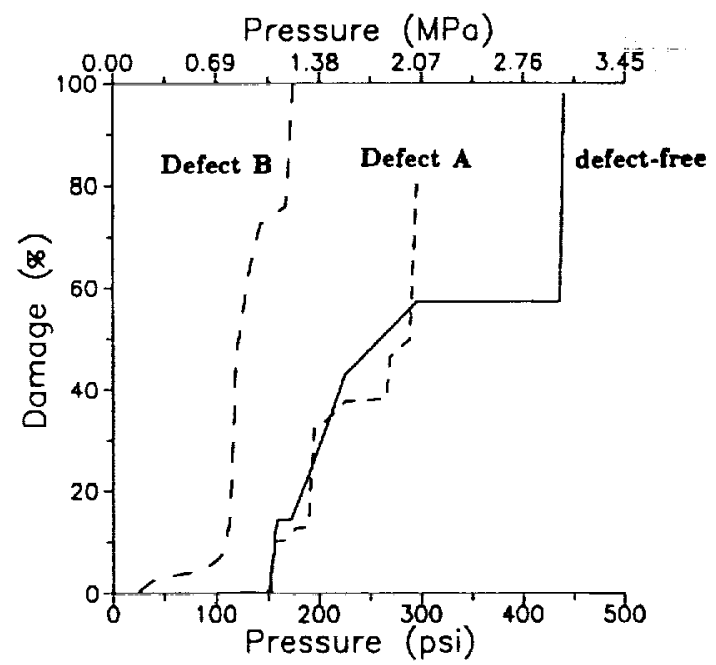

Figure 3. Damage progression in defective and defect-free shells. AS-4/HMHS $[90 / 0 / \pm 45]_{\mathrm{s}}$, diameter $=305 \mathrm{~mm}$, length $=760 \mathrm{~mm}$. Defect $A$ : initial defect is a $12.7 \mathrm{~mm}$ long axial slit. $D \theta$ fect B: compound defect that has a $95 \mathrm{~mm}(3.75 \mathrm{in})$ long axial slit superimposed on a $60 \mathrm{~mm}$ (2.36 in) long circumferential slit at half-length of the shell.

Damage Energy Release Rate (DERR) is defined as the rate of work done by external forces during structural degradation, with respect to the produced damage. DERR can be used to evaluate structural resistance against damage propagation at different stages of loading. Figure 4 shows the DERR as a function of the applied pressure on the defect-free specimen. The DERR for damage initiation is relatively low, indicating low resistance to damage initiation caused by ply transverse tensile fractures. However, after the damage initiation stage, DERR steadily increases indicating greater structural resistance against damage propagation prior to global fracture.

Figure 5 shows the DERR levels for the unstiffened specimen with a slit. The fluctuation of the DERR levels during damage propagation indicates that damage progression for the slitted shell includes consecutive relatively quick damage expansion and damage stabilization stages.

4. Stiffened, defect-free shell-Two hoop reinforcement bands were used to stiffen the shell in the circumferential direction. The reinforcements consisted of $47.5 \mathrm{~mm}$ (1.87 in) wide unidirectional AS-4/HMHS composite that was wrapped 6 plies thick. The hoop reinforcements were placed symmetrically with respect to the centerline of the shell. The center to center space between hoop reinforcements was $380 \mathrm{~mm}$ (15.0 in) as shown in Figure 6.

Damage initiation pressure for the hoop reinforced shell was $0.996 \mathrm{MPa}$ (144 psi) which is slightly lower than the pressure to initiate damage in the unreinforced shell. However, immediately after damage initiation, damage progression pressures for the hoop reinforced shell were considerably higher. Figure 7 


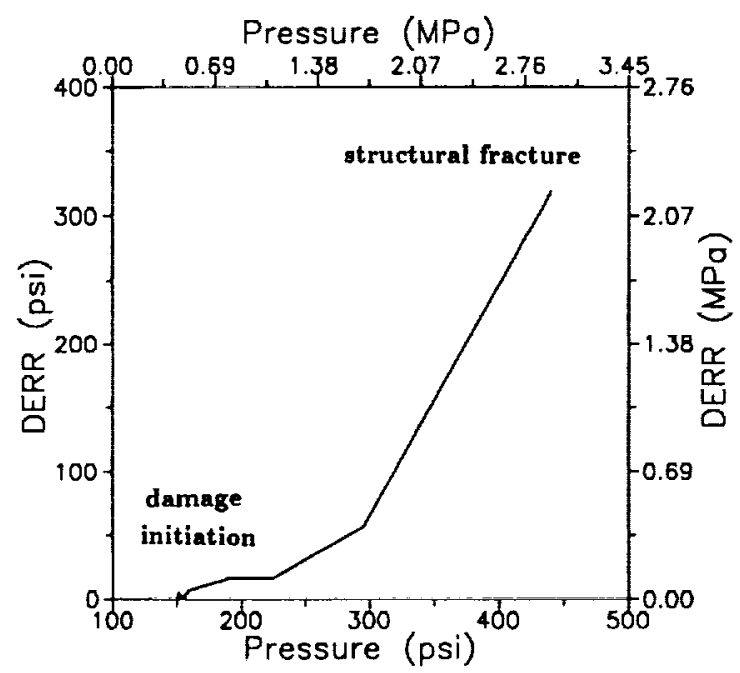

Figure 4. DERR levels for defect-free shell. AS-4/HMHS $[90 / 0 / \pm 45]_{\mathrm{s}}$, diameter $=305 \mathrm{~mm}$, length $=760 \mathrm{~mm}$.

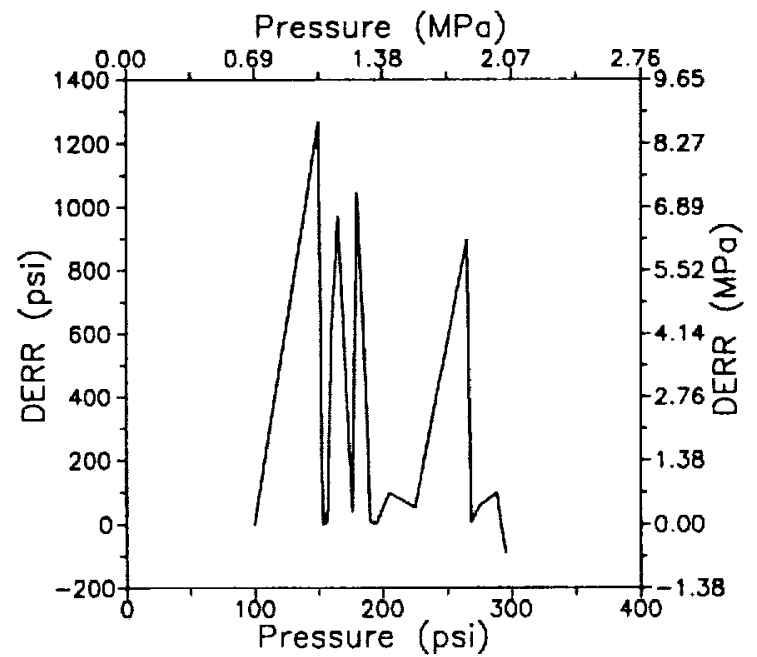

Figure 5. DERR fluctuation in defective shell. AS-4/HMHS $190 / 0 / \pm 45]_{\mathrm{s}}$, diameter $=305 \mathrm{~mm}$, length $=760 \mathrm{~mm}$, initial defect extends $12.7 \mathrm{~mm}$. 


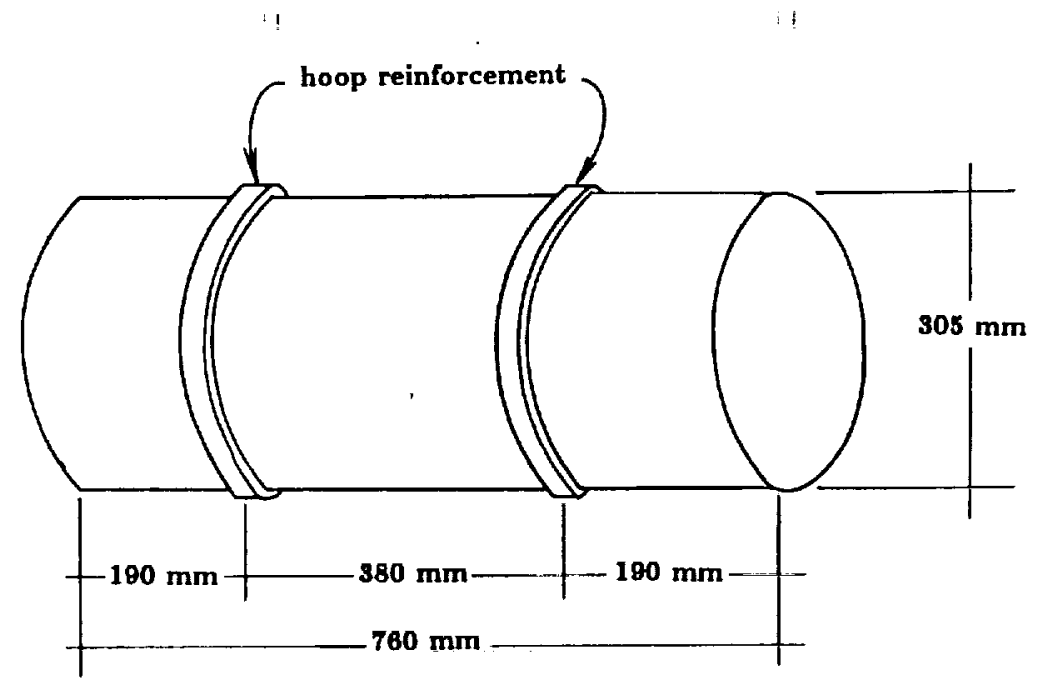

Figure 6. Hoop reinforced shell. AS-4/HMHS $[90 / 0 / \pm 45]_{\mathrm{s}}$, diameter $=305 \mathrm{~mm}$, length $=760$ $\mathrm{mm}$.

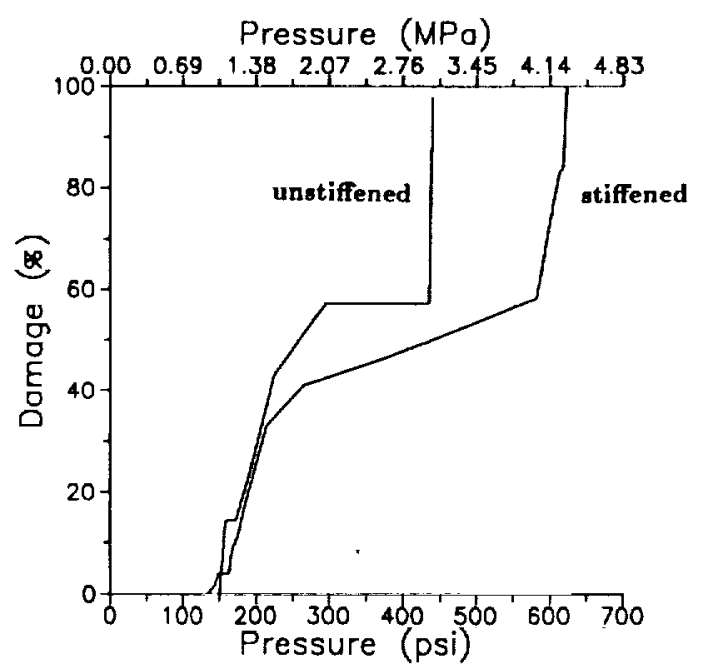

Figure 7. Effect of hoop reinforcement on damage progression. AS-4/HMHS $[90 / 0 / \pm 45]_{\mathrm{s}}$, diameter $=305 \mathrm{~mm}$, length $=760 \mathrm{~mm}$, initial defect extends $12.7 \mathrm{~mm}$. 
shows a comparison of damage progression for hoop reinforced and unreinforced shells. In particular, hoop reinforcements significantly enhanced the ultimate structural fracture performance. The burst pressure for the hoop-reinforced defect-free shell was $4.29 \mathrm{MPa}(622 \mathrm{psi})$.

5. Hoop stiffened defective shell-The shell with hoop reinforcements was considered to have a defect at midspan. The defect consisted of prescribed damage in the form of ply longitudinal fiber fractures in the first seven plies of the laminate. The defect had a length of $12.7 \mathrm{~mm}(0.5 \mathrm{in})$ along the shell axis. Damage initiation was at $0.994 \mathrm{MPa}\left(144 \mathrm{psi}\right.$ ) by ply transverse tensile fractures in the $0^{\circ}$ plies adjacent to the defect. Figure 8 shows a comparison of the performances of defective and defect-free stiffened shells. Damage initiation and progression stages involving ply transverse tensile fractures were virtually identical. However, the defective stiffened shell had a considerably lower burst pressure of $2.74 \mathrm{MPa}$ (397 psi) due to defect-induced localization of structural fracture propagation.

Table 3 summarizes the damage initiation and burst pressures for the five cases considered. For the defect-free cases, the effect of hoop stiffeners on the burst pressure may be assessed by comparing Cases 1 and 4 . The increase in the burst pressure due to hoop stiffening is $\mathbf{4 2}$ percent for the defect-free shell. For shells with minor ( $12.7 \mathrm{~mm}$ long) axial defects the effect of hoop stiffeners on the burst pressure may be assessed by comparing Cases 2 and 5 . In the presence of a minor defect the increase in the burst pressure due to hoop stiffening is 36 percent. Therefore, the presence of a defect decreases the overall benefit gained by hoop stiffening of a thin shell.

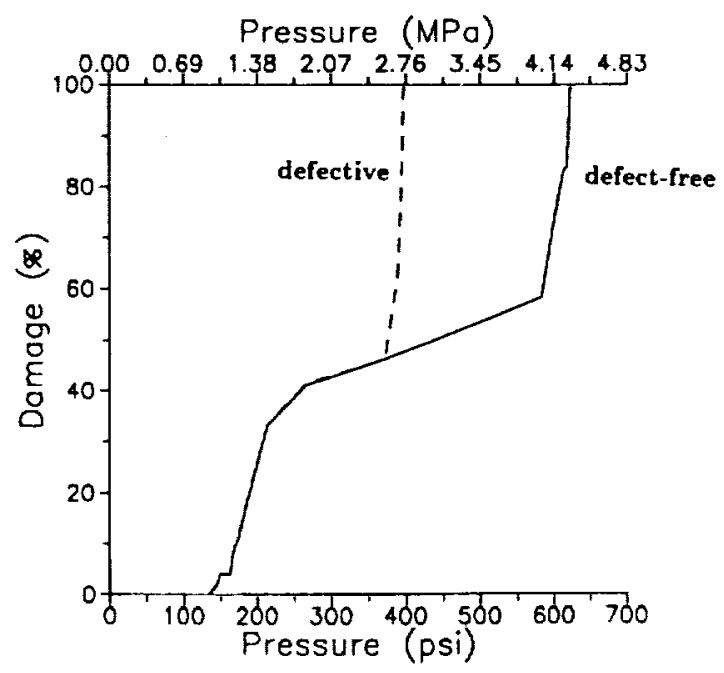

Figure 8. Effect of initial defect on damage progression in hoop reinforced shell. AS-4/HMHS $[90 / 0] \pm 45]_{\mathrm{s}}$, diameter $=305 \mathrm{~mm}$, length $760=\mathrm{mm}$, initial defect extends $12.7 \mathrm{~mm}$. 
Table 3. Damage initiation and burst pressures.

\begin{tabular}{ccccc}
\hline $\begin{array}{c}\text { Case } \\
\text { History }\end{array}$ & $\begin{array}{c}\text { Hoop } \\
\text { Stiffeners }\end{array}$ & $\begin{array}{c}\text { Defect } \\
\text { Type }\end{array}$ & $\begin{array}{c}\text { Damage Inltlation } \\
\text { Pressure (MPa) }\end{array}$ & $\begin{array}{c}\text { Burst Pressure } \\
\text { (MPa) }\end{array}$ \\
\hline 1 & No & None & 1.05 & 3.03 \\
2 & No & Minor & 1.03 & 2.01 \\
3 & No & Compound & 0.172 & 1.58 \\
4 & Yes & None & 0.996 & 4.29 \\
5 & Yes & Minor & 0.994 & 2.74 \\
\hline
\end{tabular}

\section{CONCLUSIONS}

The significant results from this investigation in which CODSTRAN (COmposite Durability STRuctural ANalysis) is used to evaluate damage growth and propagation to fracture of unstiffened and stiffened composite cylindrical shells are as follows:

1. Computational simulation, with the use of established composite mechanics and finite element modules, can be used to quantify the influence of existing defects as well as loading, on the safety and service performance of pressurized composite shell structures.

2. Damage growth and subsequent propagation to fracture for defect-free/defective, unstiffened/stiffened thin composite shells can be tracked via computational simulation.

3. Defects have a significant effect on the burst pressures of the specimens considered. Reduction of the burst pressure due to a defect depends on the size and type of the defect.

4. The damage initiation pressure can be significantly reduced due to a severe defect. However, the damage initiation pressure is not affected by a minor defect.

5. Hoop reinforcements improve the damage progression characteristics and significantly increase the burst pressures for cylindrical shells with or without minor defects. However, the percentage increase of the burst pressure due to hoop reinforcement is somewhat diminished due to the presence of defects.

6. Fracture toughness parameters such as the burst pressure and damage progression characteristics are identifiable for any pressurized composite shell structure with any defect by the demonstrated method.

\section{REFERENCES}

I. Minnetyan, L., P. L. N. Murthy and C. C. Chamis. 1990. "Composite Structure Global Fracture Toughness via Computational Simulation," Computers \& Structures, 37(2):175-180.

2. Murthy, P. L. N. and C. C. Chamis. 1986. Integrated Composite Analyzer (KCAN): Users and Programmers Manual, NASA Technical Paper 2515, March.

3. Nakazawa, S., J. B. Dias and M. S. Spiegel. 1987. MOSTUsers' Manual, Prepared for NASA I ewis Research Center by MARC Analysis Research Corp., April.

4. Minnetyan, L., C. C. Chamis and P. L. N. Murthy. 1992. "Structural Behavior of Composites with Progressive Fracture," Journal of Reinforced Plastics and Composiles, II (4):413-442. 
5. Minnetyan, L., P. L. N. Murthy and C. C. Chamis. 1992. "Progressive Fracture in Composites Subjected to Hygrothermal Environment," International Journal of Damage Mechanics, 1(1):60-79.

6. Minnetyan, L., C. C. Chamis and P. L. N. Murthy. 1991. "Damage and Fracture in Composite Thin Shells," NASA TM-105289, November.

7. Chamis, C. C., P. L. N. Murthy and L. Minnetyan. 1992. "Progressive Fracture of Polymer Matrix Composite Structures: A New Approach," NASA TM-105574, pp. 22, January.

8. Minnetyan, L., J. M Rivers, C. C Chamis and P. L. N. Murthy. 1995. "Discontinuously Stiffened Composite Panel under Compressive Loading," Journal of Reinforced Plastics and Composites. 14(1):85-98, January.

9. Ranniger, C. U. 1991. "Damage Tolerance and Arrest Characteristics of Pressurized Graphite/Epoxy Tape Cylinders," TELAC Report 9J-II, Technology Laboratory for Advanced Composites, Department of Aeronautics and Astronautics, Massachusetts Institute of Technology, 77 Massachusetts Avenue, Cambridge, Massachusetts, June. 